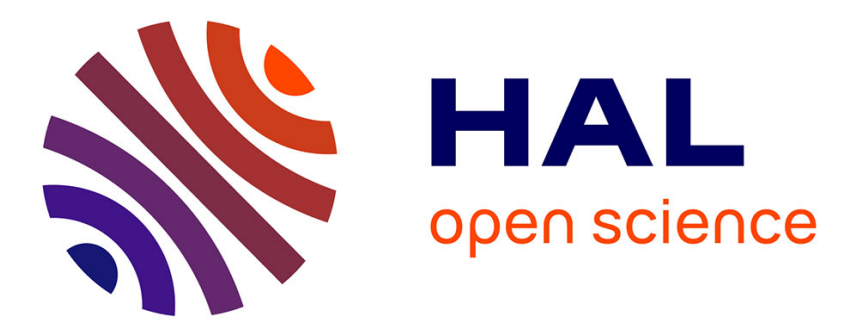

\title{
Towards Autonomic Educational Cyber Physical Systems
}

\author{
Samia Bachir, Laurent Gallon, Angel Abénia, Philippe Aniorte, Ernesto \\ Expósito
}

\section{- To cite this version:}

Samia Bachir, Laurent Gallon, Angel Abénia, Philippe Aniorte, Ernesto Expósito. Towards Autonomic Educational Cyber Physical Systems. 16th IEEE Int'l Conf. On Ubiquitous Intelligence and Computing (UIC 2019), 2019 IEEE Smart World Congress, Aug 2019, LEICESTER, United Kingdom. hal-02410339

\section{HAL Id: hal-02410339 \\ https://hal-univ-pau.archives-ouvertes.fr/hal-02410339}

Submitted on 21 Jan 2020

HAL is a multi-disciplinary open access archive for the deposit and dissemination of scientific research documents, whether they are published or not. The documents may come from teaching and research institutions in France or abroad, or from public or private research centers.
L'archive ouverte pluridisciplinaire HAL, est destinée au dépôt et à la diffusion de documents scientifiques de niveau recherche, publiés ou non, émanant des établissements d'enseignement et de recherche français ou étrangers, des laboratoires publics ou privés. 


\section{Towards Autonomic Educational Cyber Physical Systems}

\author{
Samia Bachir \\ LIUPPA Laboratory \\ University of Pau and Pays Adour \\ Pau, France \\ samia.bachir@univ-pau.fr \\ Philippe Aniorté \\ LIUPPA Laboratory \\ University of Pau and Pays Adour \\ Pau, France \\ philippe.aniorte@univ-pau.fr
}

\author{
Laurent Gallon \\ LIUPPA Laboratory \\ University of Pau and Pays Adour \\ Pau, France \\ laurent.gallon@univ-pau.fr
}

\author{
Angel Abenia \\ LIUPPA Laboratory \\ University of Pau and Pays Adour \\ Pau, France \\ angel.abenia@univ-pau.fr
}

\author{
Ernesto Exposito \\ LIUPPA Laboratory \\ University of Pau and Pays Adour \\ Pau, France \\ ernesto.exposito@univ-pau.fr
}

\begin{abstract}
University is faced with the growing challenge posed by information technology. The various learning resources supported by this latter in a connected environment have to be provided to learners according to their performances and backgrounds in the right place at the right time. In our work, we are interested in investigating key Research Questions about the next generation of university (University 4.0) relying on both the Autonomic Computing perspectives and Industry 4.0 fundamentals. The aim of our research is to build Educational Cyber Physical Systems (ECPS) where learning and teaching could occur in both virtual and physical connected spaces. In this paper, we deliver our vision of what is a University 4.0 and propose a generic layered architecture of Educational Cyber Physical System, as a key element to shape the new generation of education. The provided architecture is operational in different levels of granularity.
\end{abstract}

Index Terms-Autonomic Computing, Industry 4.0, Cyber Physical System, Educational Cyber Physical System, Layered Architecture, Education

\section{INTRODUCTION}

Since information technology emerged in our everyday lives, the educational community have started exploring the potential adoption of analogous techniques in some domains to improve learning and teaching processes. For instance, business intelligence and data analytics, from a commercial perspective, gave rise to educational data mining and learning analytics. The capacity to evolve in such a way requires a significant effort to proceed in such a whole and complex process. Likewise, we are interested in investigating key Research Questions about University 4.0 build upon Autonomic Computing perspectives and Industry 4.0 fundamentals applied to the different educational processes.

In developed countries, as part of a continuous effort to bring Technology Enhanced Learning Environments (TELE) throughout the educational system, a long historical quest has been pursued to set out landmarks concerning education policies. In the literature, TELE is defined as the study of how we learn and teach with interactive technologies, and how to design and evaluate effective technologies for learning [11]. Different manners were proposed to classify TELE. We have identified the following categorisation: learning theories (Bihaviorism, Constructivism, etc.) [12], [20], different perspectives (pedagogical, cognitive, social and epistemological, etc.) [2], and computational tools (Intelligent Tutoring System (ITS), Massive Open Online Courses (MOOCs), Computer Supported Collaborative Learning, etc.). The conducted research works were more interested in enhancing and adapting learning content within a particular system that aims to attend prefixed learning objectives within a short and predefined time. That considerable effort has been widely acknowledged in the literature despite the ad-hoc development conduct. For instance, ITS, as defined by Brooks [3], is a problem solving system that can assist and help to produce feedback and hints to learners based on AI techniques. However the assistance and intelligent tutorial dialogues for scaffolding problem solving are available for a very specific domain of knowledge within a limited time.

Continuous efforts are still required to respond to university current challenges and students' needs. For this purpose, we are eager to contribute in the establishment of a smart connected environment to support students and the different educational stockholders for a better decision making in education within different learning processes. Actually, one 's university journey is no longer fixed by a prior defined path. Students can decide reorientation almost wherever they want. This flexibility generates different gateways between educational pathways. Students coming from different backgrounds find themselves together attending the same courses without any personalisation according to their profiles (background, performances, etc.). For instance, students are not able to exempt some courses because they followed the same training before. Also, the possibility of undertaking further courses to deepen their knowledge in a particular domain is not available. We consider these issues as one of the main reasons 
of students' motivation and perseverance at university which generate failure and drop out.

Our goal is to set up a connected environment, based on the Internet of Everything (IoE) paradigm [8], where we gather objects (TEL systems, physical learning resources, smart objects, etc), people (students, teachers, etc.) and data in order to adjust learning processes according to the learners' requirements and the teaching/learning context as well. Three types of learning processes could take place at an educational context (university in our case): (1) classroom process which refer to a pedagogical scenario implemented in a classroom, (2) course process which refer to the strategy of designing a course according to the knowledge-to-be-taught, (3) curriculum processes which refer to the whole curriculum composed by the different courses that a student follows in a long term perspective.

Setting up such environment seems obviously a challenging task. Conducted contributions within University 3.0 by TEL environments (e.g learning resources) require orchestration between each others to reform their ad-hoc use. Another challenge consists on assisting, (semi-) automatically, humans (e.g teachers, administrators, etc.) to make decisions about adapting the learning processes of students. For this purpose, we are eager to investigate the following main Research Question : How learning processes could be adapted and orchestrated according to learners' profiles and learning/teaching contexts in order to improve the achievement of learning objectives, to personalise and optimise the whole learning experience for each student, in a smart connected environment based on the IoE paradigm?

In doing so, we started our investigation by proposing a holistic vision of University 4.0. Then, we present a generic layered architecture of Educational Cyber Physical Systems (ECPS) which could be implemented in different levels of granularity. Afterwards, we specify three different uses of ECPS. The first level (classroom process) will represent several instances of different courses progress in a blended context. The second level (course process) implements accordingly an ECPS orchestrator, based on the first level, to coordinate the transitions between both available and required sessions for an optimised and personalised course. Accordingly, another ECPS orchestrates the curriculum process based on the followed courses.

The remainder of this paper is structured as follows: In section II, we describe the background elements and explore the potential relationship between Autonomic Computing and Industry 4.0. Section III discusses a global vision of University 4.0, a generic layered architecture of Educational Cyber Physical Systems and its eventual use in different levels of granularity. Finally, the conclusion and future works are drawn in section IV.

\section{BACKGROUND AND RELATED WORKS}

\section{A. Autonomic Computing (AC)}

Inspired by the autonomic nervous system, IBM researchers [7] are often acknowledged with initiating the Autonomic

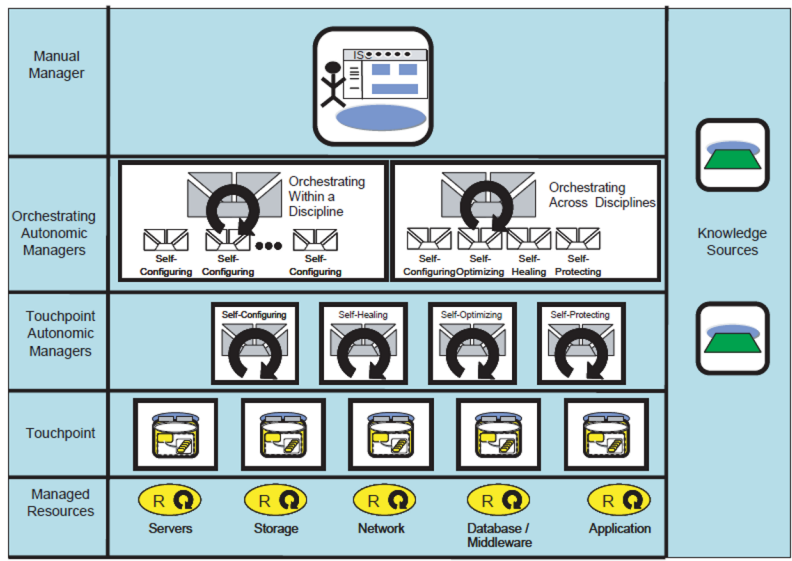

Q Intelligent Control Loop

Fig. 1. Autonomic Computing Reference Architecture [7]

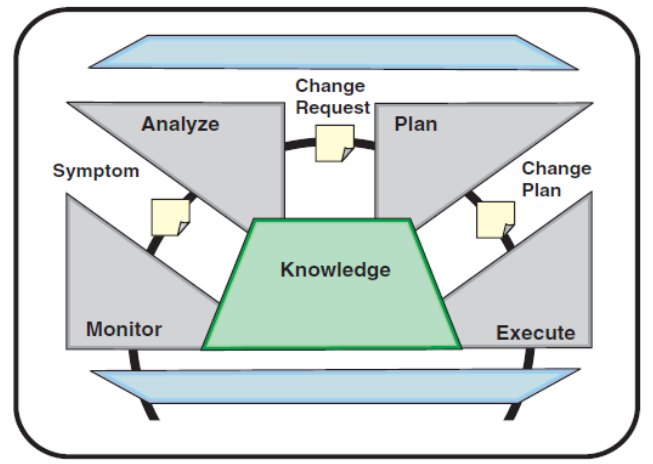

Fig. 2. Control Loop process [7]

Computing blueprint. As defined in [22], AC is considered as a holistic vision of self-managing capabilities in a system. These capabilities cover different aspects of self-management that implement control loops (monitor, analyse, plan and execute), as shown in Fig.1 and Fig.2, which collect details from the system and act accordingly, as stated in [7]. Selfconfiguring AC capacity allows the dynamic adaptation to changes in the environment. The self-healing capacity ensures the performance of a system by detecting the system malfunction. The automated reallocation of resources is handled with a self-optimising capability. Security issues are supported by a self-protecting capability. Add to further self-managing capabilities, the listed ones are often the most referred in the AC field. They are implemented through different autonomic managers. In our work, we rely on the reference architecture of the IBM blueprint. As it is shown in Fig. 1, managed resources (Hardware and Software) represent the IT infrastructure in which the correspondent sensors and actuators are implemented by touchpoints. Both layers (three and four) implement control loops via autonomic managers according to different levels. Each of which implements some portion of the automation process. In level three, a managed resource could be conducted by one or multiple autonomic managers. Layer four orchestrates other autonomic managers from layer three. 


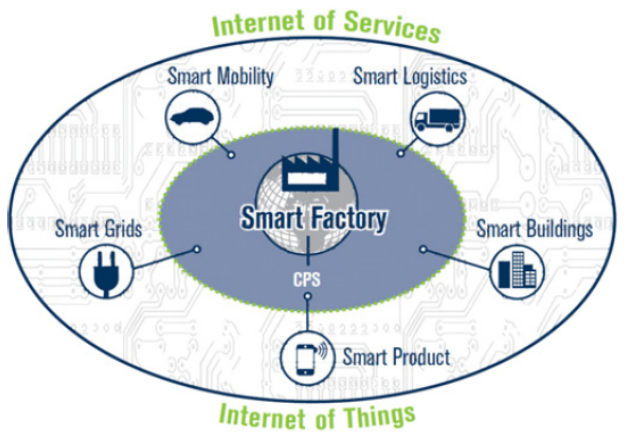

Fig. 3. Industry 4.0 [16]

All the different layers manage data through the knowledge source, where standardisation efforts are still challenging. In the top level of the architecture, a system management interface is offered to IT professionals with an integrated solution.

AC principles were also stressed by other research fields (e.g. Distributed Computing, Multi Agent System). But it is worth pointing out that the intelligent control loops are implemented in different levels within, especially, an AC system. It could even be integrated within a managed resource. We consider this characteristic as a primary motivation to rely on $\mathrm{AC}$ vision and propose our reflection of what could be an autonomic manager in an educational context to propose an adaptation of learning processes.

Control loops could be incorporated within a particular managed resource, or in a second level by autonomic managers to allow the execution of self-managing capacities (selfconfiguring, self-healing, self-optimising, self-protecting), or in a high level of orchestration. Similarly, we find the same levels of decision making at university. In fact, it could be incorporated within a particular learning resources (e.g. a learning system), or happened during a classroom course to allocate learning resources according to students behavior, or in a high administrative level where adaptation of the whole curriculum could be generated, etc. Hence, we rely on Autonomic Computing to establish the similar viewpoints of control loops within ECPS which we consider the key element of University 4.0.

\section{B. Industry 4.0}

Multiple research works have been interested in the field of Industry 4.0 since the rise of the concept in 2011 amongst the German industrial community. Industry 4.0 is a complex initiative that embraces several partially overlapping areas [15]. It was defined by Herman et al. [14] as the integration of complex physical machinery and devices with networked sensors and software, used to predict, control and plan for better business and societal outcomes. In such manufacturing environment, smart machines, installations, workpieces and other components will exchange data and information in real time which represents a shift from rigid, centralised factory control systems to decentralised intelligence. New business

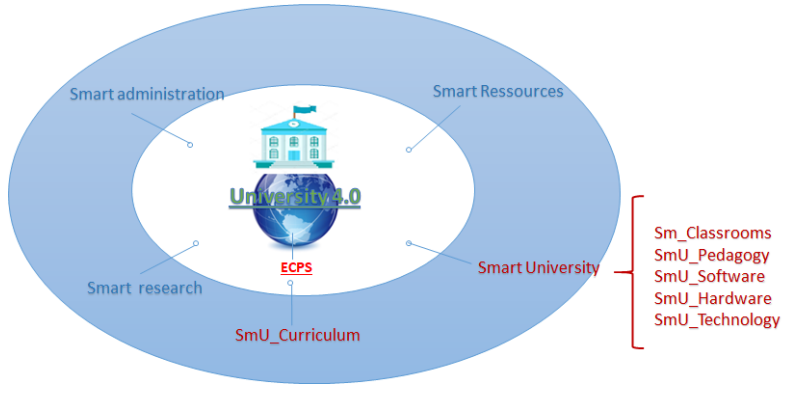

Fig. 4. University 4.0

models and new models for cooperation constitute the real added value of Industry 4.0 [9].

From a historical perspective, three industrial generations preceded this revolution. From the introduction of mechanical production facilities, to the electrification and the division of labor, to the automation of production processes, throughout the centuries, the idea of smart manufacturing appears to deliver fundamental improvements to the industrial processes involved in manufacturing, engineering, material usage and supply chain and life cycle management ( [10], [14]).

Hermann et al. [14] identified four design principles of Industry 4.0. An interconnection aspect, Internet of Everything, to support collaboration between and within different stakeholders (human-human, human-machine, and machinemachine [25]). Information transparency will be insured due to the fact that a virtual copy of the physical world is regularly generated. Decentralised decisions are enabled by CPS which allow the monitoring and control of the physical world autonomously through their embedded computers, sensors and actuators [17]. Humans are supported with a technical assistance in order to intervene when needed.

CPS are among the key elements in the field of Industry 4.0, as depicted in Fig.3. According to [14], these are systems which make a fusion of a virtual and physical world possible. They monitor and control the physical processes. A 5C architecture was proposed in [18] in which authors specify two main functional components of CPS. The first one consists in the advanced connectivity that ensures real-time data acquisition from the physical world and information feedback from the cyber space. The second functionality resides on intelligent data management, analytics and computational capability that constructs the cyber space. Various features were identified in [13] that make the difference to CPS, comparing them to conventional system, like the time-sensitive combination of the cyber and the physical, and their connectedness. A consistency between Cyber Physical Systems and autonomic managers is emerged through an intelligent aspect with feedback loops where physical processes affect computations and vice versa.

In addition to the $\mathrm{AC}$ perspective, this vision of giving rise to a forth industrial revolution based on key elements (CPS, Internet of Things, Cloud Computing, etc.) leads us also to rethink the new generation of education which is specified in the following section. By new generation of education, we mean the smart capacity to adapt learning and teaching 
processes according to the Internet of Everythings elements (people, objects, data, processes and learning/teaching context). According to [8], IoE is the next evolutionary step of Internet of Things where not only embedded devices are making up the network but also people, processes and data have to be taken into account.

\section{CONTRIBUtion}

\section{A. University 4.0 - Definition}

As a result of the accelerating digitalisation of modern society, research works have been interested in the future of education in order to adjust it according to the potential of technology. As stated in [19], the main idea of an innovative smart society will be the development of human potential. Various emerging concepts (Smart education [19], Education 4.0 [6], Smart university [26]) have been proposed in relation to this purpose. Education 4.0 for instance focuses more on innovative educational content from a didactical perspective. Its aim is the training of future professionals who will be working in an Industry 4.0 context. New skills, learning and training concepts as well as the flexibility in education are considered necessary.

In our work, we build upon ideas from both the fourth industrial revolution principles and $\mathrm{AC}$ vision in order to define University 4.0, as a connected educational system. To the best of our knowledge, this is the first research work that aims to define such concept and propose a holistic vision of it. Conducted researches with TELE have brought important contributions to revolutionise education, as it was presented in the previous section. However, pedagogical models are still linear as it focuses mainly on short-term learning especially when it comes to a specific learning system. As IoE are being incorporated in our daily lives, we consider University 4.0 as an intelligent integration of learning and teaching processes, devices with networked sensors and software, educational stackholders, and correspondent data used to monitor, analyse, plan, control and react for better education and societal outcomes according to the educational context. This intelligent integration is ensured by Educational Cyber Physical System (ECPS). Add to educational features, smart administration, smart research and smart resources are also parts of University 4.0 (Fig. 4). We consider that ECPS are key components behind the smartness of each part of University 4.0. In our work, we only focus on the educational part.

Since the emergence of smart and ubiquitous learning environments, many research studies have been interested in integrating the Internet of Things in educational context. We classified them into three categories (learning/teaching of IoT, learning/teaching by IoT, learning/teaching based on IoT) in a previous research work. Conducted contributions ( [23], [24], [4], [27], [21], [6], etc.) have been almost dealing with IoT as a body of knowledge to be taught or as an artifact used to learn or teach other knowledge. However, there is no interest in using IoT in order to monitor the learning experience by its different types of processes to adapt them. For instance, in [26], a conceptual definition of smart university was given. It was defined as an n-tuple of $n$ elements that can be constituted from; smart features (adaption, sensing, inferring, self learning, anticipation, self-optimising or re-structuring), smart stackholders, smart curriculum, smart pedagogy, smart classrooms, smart hardware and software, and smart technology and resources. The "smartness" of smart university is limited to the organisation and deployment of modern technological devices within connected features. More importantly, it should be implemented to support both learning and teaching activities more intelligently to generate the suitable pedagogical scenario regarding learning objectives and students' performances. We basically rely on this conceptual definition of smart university to merge it with the different features of ECPS. A detailed description of ECPS is highlighted below.

\section{B. Educational Cyber Physical System (ECPS)}

1) Definition: Many research works have been interested in Cyber Physical Systems and their exponential applications in various domains (Industry, Healthcare, Energy, etc.). But there are hardly studies which have dealt with their potential use in Education. In [5], the authors define an ECPS as a localised system involving software (cyber) and physical (experimental) resources or a more advanced distributed collaborative system. We relatively agree with the provided definition. Relating to the provided University 4.0 holistic vision, we consider ECPS as system capable of contextualizing the different physical elements of the IoE educational ecosystem (people, objects) to generate the required processes that should be implemented based on a particular data processing which highly depends on the learning/teaching context. Data collection and analysis are in the cyber level in order to monitor and supervise the physical world and adapt the processes when it is needed. This monitoring is based on executing control loops (monitor, analyse, plan and execute), induced from the Autonomic Computing perspective. ECPS are network of cyber-physical components within an IoE educational ecosystem, where the aim is to improve not only the learning and teaching processes, but also the whole educational ecosystem. At different operational levels, ECPS implement control loops (monitor, analyse, plan and execute)to self-adapt curriculum and pedagogical situations depending on student skills, student capacities and student run-time evolution, etc.

2) Generic Architecture: In view of our main Research Question on adapting and optimising the learning processes for student, we consider that control loops could occur in different levels throughout the educational system. From a top level (curriculum process) until an implemented pedagogical scenario in classrooms, different parameters are involved to decide about a required improvement or an educational request. But the control loop (monitor, analyse, plan, execute) aspect is typically the same applied into different managed data. In this paper, we identify three different levels of ECPS execution. The first one presents a low level of decision which interests in implemented pedagogical scenario during classroom courses. We find almost the same layered architecture (Fig.5) at a 


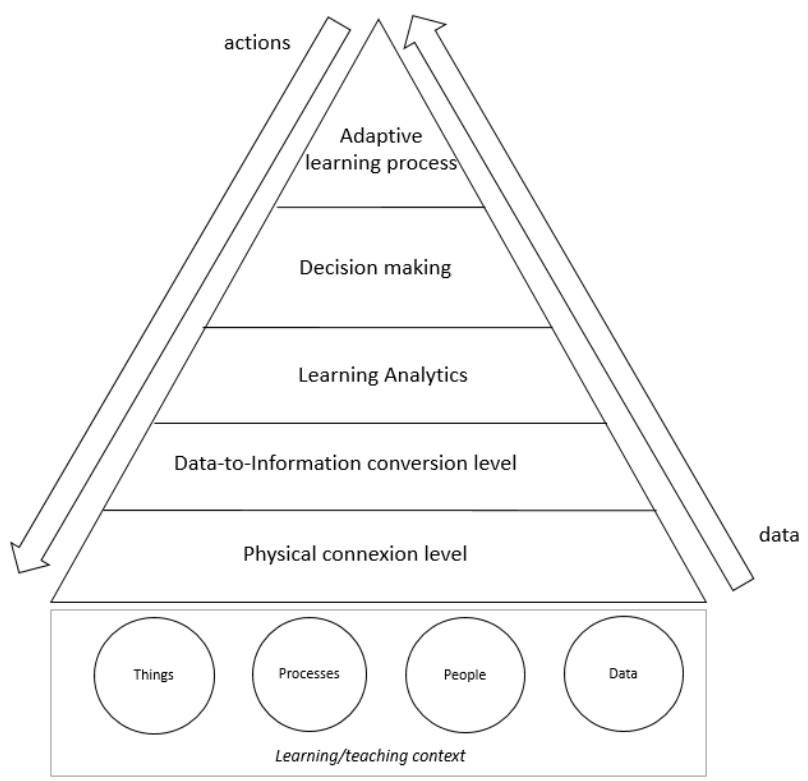

Fig. 5. Generic Layered Architecture of Educational Cyber Physical System

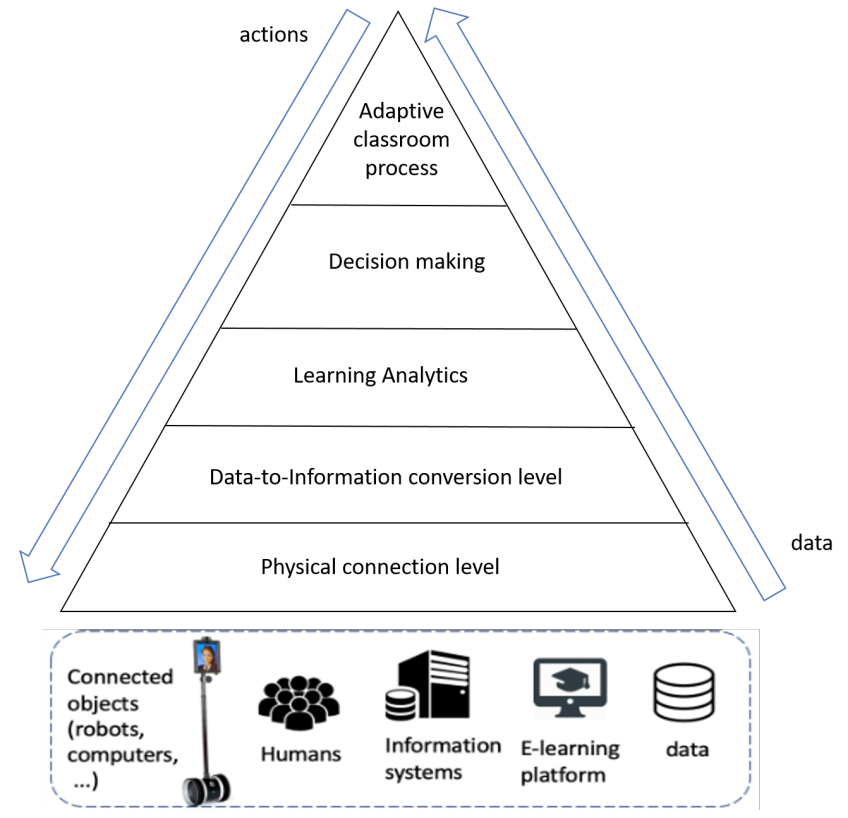

Fig. 6. Educational Cyber Physical System in classroom process

high level of decision making where orchestrating ECPS (Course ECPS and Curriculum ECPS) are implemented to support the various self-Managing features and adapt either the course process or the whole curriculum process. It is worth mentioning that ECPS implemented layers differ mainly in the physical connection level, monitored data and the generated adapted learning process as parts of the learning and teaching context. The followings will specify with more in details both the utility and implementation of each layer.

3) Classroom ECPS: The Fig.6 proposes the use of the generic layered architecture in a classroom level implementation. The basic layer consists of a set of both physical and virtual resources. This mixture of different natures of managed resources strengthen blended learning. The aim is to bring together a sort of everything (Human resources, connected objects, information system, TEL Systems, data ) to ensure the capacity to respond to any request for adapting a pedagogical scenario for a student.

This network of different elements composes Internet of Everything ensured by the physical connection level (Layer I). Collected data from different resources are transformed to information by layer II. Unified form of information allows flexibility and interoperability in the process. Data analytics are made through Layer III which analyses and treats the different flows of information in real time and proposes aggregated information and meaningful knowledge for layer IV. The aim of this latter is to make decisions according to the interpreted information. Artificial Intelligence techniques are behind the decision making process that leads to change an initial planned process or a reconfiguration of managed resources. Level $\mathrm{V}$ explicitly shows the adaptation and reconfiguration capacity of learning processes. The bidirectional data flow represents control loops around the different ECPS layers.

To illustrate, we give a typical example of use at the university where different courses have to be followed by students in both face-to-face and distant ways. Each course for each student is implemented by a classroom ECPS in a given time. For face-to-face students, it is composed with a smart classroom which is equipped with many connected objects that represent the physical layer: e.g. computers, local networks, cameras, etc. In the case of distant student, it is composed with the same components, but it also contains secure access to the university's network (VPN capabilities) and a telepresence robot for social interactions.

Data is collected during the progress of the activity, from the resources allocated to each classroom ECPS. It must be stored in a common format in a data warehouse, and will be analysed to deduce knowledge/know-how validation, but also the level of engagement of the (tele-)present student. Peer and teacher interactions in the classroom are also a major indicator of the effectiveness of the learning process.

The interoperability of data and the generation of dashboards that monitor student progress are supported by a Learning Analytics platform, as for example Apereo [1] (Layer 2 and 3). Layer 4 orders the pedagogical situations foreseen in the adapted classroom scenario (layer 5). For example, if the student moves a lot with the robot, but does not progress in the learning activity, it means that she/he has a problem (understanding, difficulty of situations to achieve, difficulty of use of the robot, etc.). An Intelligent Tutoring System (ITS), or a specialised chatbot can be activated to help her/him. An intervention from the physical tutor may also be required in certain cases. These examples demonstrate the capabilities of self-configuring of a classroom ECPS.

The example of face-to-face and distant students in the same pedagogical situation has been implemented in our university (layers 1 and 2 only) so that a student who is unavailable 


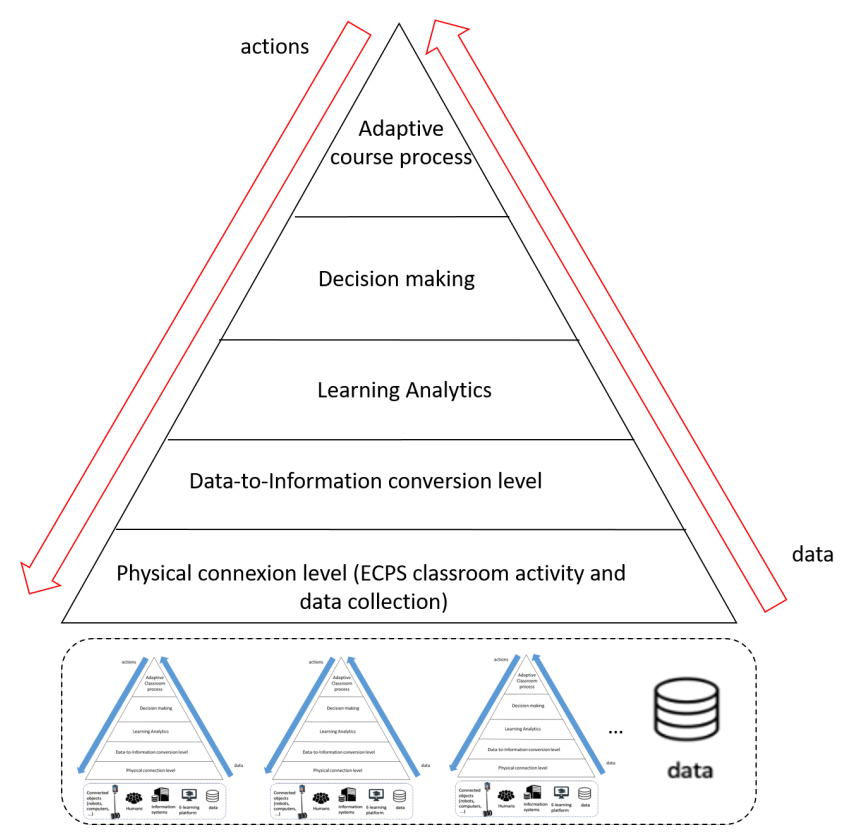

Fig. 7. Educational Cyber Physical System in course process

can remotely follow a whole course including its examination, using a telepresence robot ${ }^{1}$. The same room was used by a remote teacher for the realisation of a practical assignment of the same course. The high level of both decision making and adaptive scenario was handled manually by the teacher. We are currently working to establish a semi/automatic processing of these layers and coupled it with what we have conducted at this stage.

4) Course ECPS: Despite the fact that this process has a didactic perspective, the monitoring of course learning adaptation seems important for students in order to add/delete useful/unnecessary learning sessions according to students needs. Monitoring this kind of learning process ensures the achievement of learning objectives and thus the required competences within a particular course. ECPS course (Fig.7) is based on data collected from ECPS classroom and further data about the learning/teaching context as well in order to boost and enhance the efficiency of a course and its correspondent sessions design.

5) Curriculum ECPS: Once different instances of ECPS courses occur in different contexts (different courses in different classrooms), an ECPS orchestrator, as illustrated in Fig.8, executes almost the same stages as in Fig.7 but from another perspective. In fact, managed resources in a high level of learning process management will no longer be focused on physical resources (connected objects, humans, learning systems, data, ... ) but rather on meta-data traced back from different instances of ECPS.

The network of ECPS courses coupled with further data (e.g. Competence portfolio) lead to a decision making about the whole curriculum process. Based on the competence port-

\footnotetext{
${ }^{1}$ https://youtu.be/zbhjatbalaw (French)
}

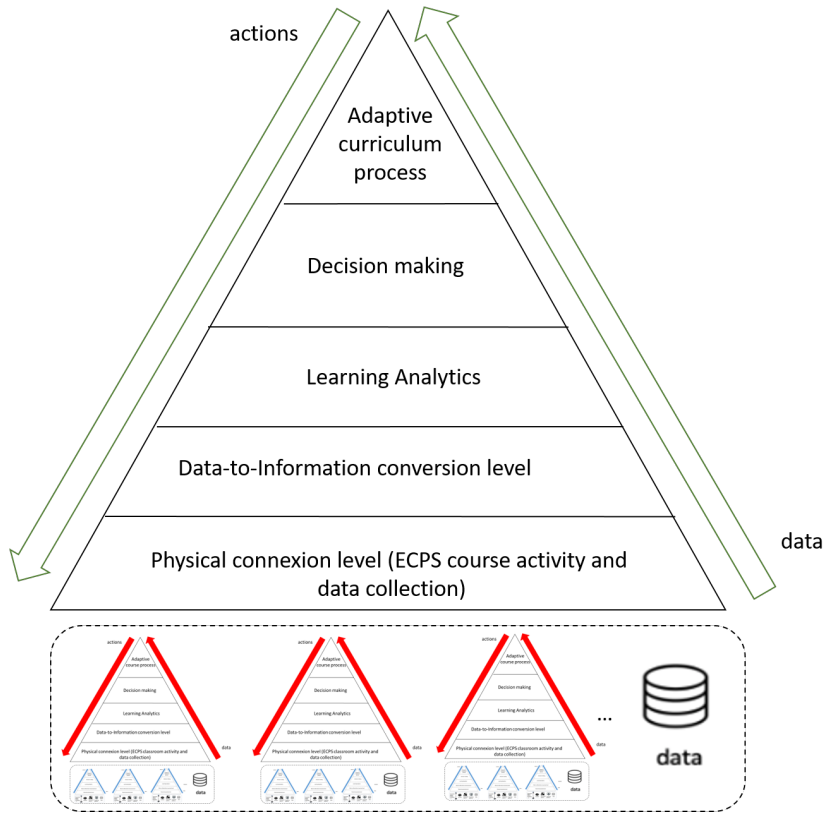

Fig. 8. Educational Cyber Physical System in curriculum process

folio and further data from other information system, we could be able to determine if, for example, a student shall upgrade his/her knowledge in a particular subject. This improvement could be ensured by attending a MOOC to deepen students knowledge or, in the worst case, attending another course. Hence the concept of such orchestrator ECPS is supposed to automatically adapt the generic curriculum to each student based mainly on the acquired competences for a long-term expertise acquisition.

\section{CONCLusion And Future Works}

Driven by the need to support university students with an adequate infrastructure, current literature on Technology Enhanced Learning mainly focuses on the value of Learning regardless the specific infrastructure of university as an important institution facing many challenges. In this perspective, we are interested to rethink university with regard to other discipline evolution due to the Internet of Everythings expansion in our daily lives. Accordingly, this work-in-progress paper begins by considering the different background elements. Then, we provide a holistic vision of what we consider as University 4.0 followed by a generic layered architecture of ECPS, as a key element of it, and three different instantiations (classroom, course and curriculum ECPS). The proposed architecture seems very promising as different levels of granularity could be laid out throughout the different layers. Given that we defined at this stage ECPS generic layered architecture, we are currently working to propose the required Software Architecture of such system by the bias of a model-driven tool. Accordingly, we will define the different modeling tools and generate the required meta-models from different view points. 


\section{REFERENCES}

[1] Apereo, https://www.apereo.org/, 2016 (accessed January 27, 2019).

[2] Rosa M. Bottino. Which perspectives can drive the analysis of technology-enhanced learning environments? IGI Global, pages 172184, 2014.

[3] Christopher Brooks, Jim Greer, Erica Melis, and Carsten Ullrich. Combining its and elearning technologies: Opportunities and challenges. In Int. Conf. on Intelligent Tutoring Systems, pages 278-287, 2006.

[4] Barry Burd, Lecia Barker, Monica Divitini, Felix Armando Fermin Perez, Ingrid Russell, Bill Siever, and Liviana Tudor. Courses, content, and tools for internet of things in computer science education. In Proceedings of the 2017 ITiCSE Conference on Working Group Reports, pages 125-139. ACM, 2018.

[5] Joe Cecil and Damon Chandler. Cyber physical systems and technologies for next generation e-learning activities. CPS and Technologies for Next Generation e-Learning Activities, (10):1-11, 2014.

[6] Monica Ciolacu, Paul Mugur Svasta, Waldemar Berg, and Heribert Popp. Education 4.0 for tall thin engineer in a data driven society. In Design and Technology in Electronic Packaging (SIITME), 2017 IEEE 23rd International Symposium for, pages 432-437. IEEE, 2017.

[7] Autonomic Computing et al. An architectural blueprint for autonomic computing. IBM White Paper, 31:1-6, 2006.

[8] Rafael de Amorim Silva and Rosana TV Braga. An acknowledged system of systems for educational internet of everything ecosystems. In Proceedings of the 12th European Conference on Software Architecture: Companion Proceedings, page 25. ACM, 2018.

[9] Peter de Lange, Boris Bähre, Christiane Finetti-Imhof, Ralf Klamma, Andreas Koch, and Leif Oppermann. Socio-technical challenges in the digital gap between building information modeling and industry 4.0 In Proceedings of the 3rd International Workshop on Socio-Technical Perspective in IS development (STPIS'17) co-located with (CAiSE 2017), Essen, Germany, June 13, 2017., pages 33-46, 2017.

[10] Rainer Drath and Alexander Horch. Industrie 4.0: Hit or hype?[industry forum]. IEEE industrial electronics magazine, 8(2):56-58, 2014.

[11] Erik Duval, Mike Sharples, and Rosamund Sutherland. Research themes in technology enhanced learning. In Technology Enhanced Learning, pages 1-10. Springer, 2017.

[12] Resnick L Greeno JG, Collins AM. Cognition and Learning. In the Handbook of Educational Psychology, 1996.

[13] Cyber Physical Systems Public Working Group. Framework for cyberphysical systems, release 1.0. National Institute for Standards and Technology, pages 1-266, 2016.

[14] Mario Hermann, Tobias Pentek, and Boris Otto. Design principles for industrie 4.0 scenarios. In System Sciences (HICSS), 2016 49th Hawaii International Conference on, pages 3928-3937. IEEE, 2016.

[15] H Kagermann, W Wahlster, and J Helbig. Final report of the industrie 4.0 working group. Federal Ministry of Education and Research, 2013.

[16] Seok Kang, Yeon Lee, SangSu Choi, Hyun Kim, Hee Park, Yeon Son, Hyun Kim, and Sang Do. Smart manufacturing: Past research, present findings, and future directions. International Journal of Precision Engineering and Manufacturing-Green Technology, 3(1):111-128, 2016.

[17] Edward A Lee. Cyber physical systems: Design challenges. In 11th IEEE Symposium on Object Oriented Real-Time Distributed Computing (ISORC), pages 363-369. IEEE, 2008.

[18] Jay Lee, Behrad Bagheri, and Hung-An Kao. A cyber-physical systems architecture for industry 4.0-based manufacturing systems. Manufacturing Letters, 3:18-23, 2015.

[19] Irina Makarova, Ksenia Shubenkova, Polina Buyvol, Vadim Mavrin, and Eduard Mukhametdinov. Interaction between education and business in digital era. In 2018 IEEE Industrial Cyber-Physical Systems (ICPS), pages 503-508. IEEE, 2018.

[20] Terry Mayes and Sara De Freitas. Review of e-learning theories, frameworks and models. JISC e-learning models desk study, (1), 2004

[21] Filipe T Moreira, Andreia Magalhães, Fernando Ramos, and Mário Vairinhos. The power of the internet of things in education: an overview of current status and potential. In Conference on Smart Learning Ecosystems and Regional Development, pages 51-63. Springer, 2017.

[22] Mohammad Reza Nami and Koen Bertels. A survey of autonomic computing systems. In Autonomic and Autonomous Systems, 2007. ICAS07. Third International Conference on, pages 26-26. IEEE, 2007.

[23] Vichian Puncreobutr. Education 4.0: new challenge of learning. St. Theresa Journal of Humanities and Social Sciences, 2(2), 2016.
[24] Samuel Mensah Sackey, Andre Bester, and Dennit Adams. Industry 4.0 learning factory didactic design parameters for industrial engineering education in south africa. South African Journal of Industrial Engineering, 28(1):114-124, 2017

[25] G Schuh, T Potente, C Wesch-Potente, and A Hauptvogel. 10.6 sustainable increase of overhead productivity due to cyber-physicalsystems. 2013.

[26] Vladimir L Uskov, Jeffrey P Bakken, Srinivas Karri, Alexander V Uskov, Colleen Heinemann, and Rama Rachakonda. Smart university: Conceptual modeling and systems design. In International Conference on Smart Education and Smart E-Learning, pages 49-86, 2017.

[27] YANG Yuqiao and YU Kanhua. Construction of distance education classroom in architecture specialty based on internet of things technology. International Journal of Emerging Technologies in Learning (iJET), 11(05):56-61, 2016. 